\title{
A Cross-sectional Clinic-based Study Exploring whether Variants within Genes Coding for Enzymes of the Transmethylation and Trans-sulphuration Pathways Are Associated with Inter-individual Phenotypic Variation in Sickle Cell Anaemia in Jamaica

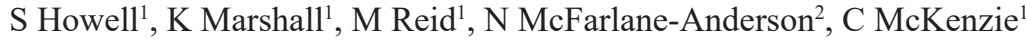

\begin{abstract}
Objective: To explore potential associations between four biallelic variants within three genes that code for enzymes involved in either the transmethylation (methylene tetrahydrofolate reductase (MTHFR), 5-methyltetrahydrofolate-homocysteine methyltransferase (MTR)) or trans-sulphuration (cystathionine beta-synthase (CBS)) metabolic pathways, and clinically relevant phenotypic measures in sickle cell anaemia [homozygous haemoglobin SS] (HbSS).

Methods: A total of 371 participants with HbSS disease were recruited from the Sickle Cell Clinic of the Sickle Cell Unit at The University of the West Indies, Mona, Jamaica. Genotypes at four sites (MTHFR C677T, MTHFR A1298C, MTR A2756G and CBS 844ins68) within the three genes were determined using polymerase chain reaction-based assays.

Results: Univariate regression analyses showed statistically significant associations between MTHFR C677T and red blood cell (RBC) count $(\mathrm{p}=0.019)$ and between MTHFR C677T and mean corpuscular volume $(\mathrm{p}=0.015)$. Multivariable regression analyses showed statistically significant associations between MTHFR C677T and packed cell volume values ( $\mathrm{p}=0.019)$, between MTHFR C677T and RBC count ( $\mathrm{p}=0.013)$, and between MTHFR A1298C and mean corpuscular haemoglobin concentration $(\mathrm{p}=0.026)$.

Conclusion: This exploratory cross-sectional study has generated novel and informative genotype-phenotype estimates of association, but larger studies are needed to determine whether the specific variants within these genes underlying the transmethylation and trans-sulphuration pathways are related to inter-individual phenotypic variability in HbSS.
\end{abstract}

Keywords: Genetic variants, phenotypic variation, sickle cell anaemia

From: ${ }^{1}$ Tropical Metabolism Research Unit, Caribbean Institute for Health Research (formerly Tropical Medicine Research Institute), The University of the West Indies, Mona, Jamaica, West Indies and ${ }^{2}$ Department of Basic Medical Sciences, The University of the West Indies, Mona, Jamaica, West Indies.
Correspondence: Dr K Marshall, Tropical Metabolism Research Unit, Caribbean Institute for Health Research, The University of the West Indies, Mona, Kingston 7, Jamaica, West Indies. Email: kwesi.marshall@uwimona.edu.jm 


\title{
Estudio transversal de carácter clínico que explora si las variantes de genes que codifican las enzimas de las vías de transmetilación y trans-sulfuración están asociadas con la variación fenotípica interindividual en la anemia de células falciformes en Jamaica
}

\author{
S Howell $^{1}$, K Marshall ${ }^{1}$, M Reid ${ }^{1}$, N McFarlane-Anderson ${ }^{2}$, C McKenzie ${ }^{1}$
}

\begin{abstract}
RESUMEN
Objetivo: Explorar las posibles asociaciones entre cuatro variantes bialélicas en tres genes que codifican las enzimas involucradas en la transmetilación (metilentetrahidrofolato reductasa (MTHFR), 5-metiltetrahidrofolato-homocisteína metiltransferasa (MTR)), o la transulfuración (cistationina beta-sintasa (CBS)), y explorar las medidas fenotípicas clínicamente relevantes en la anemia de células falciformes [hemoglobina homocigótica SS] (HbSS).

Métodos: Un total de 371 pacientes con la enfermedad HbSS fueron reclutados de la Clínica de Células Falciformes de la Unidad de Células Falciformes en la Universidad de West Indies, Mona, Jamaica. Los genotipos en los cuatro sitios (MTHFR C677T, MTHFR A1298C, MTR A2756G, y CBS 844ins68) de los tres genes fueron determinados mediante ensayos de reacción en cadena de la polimerasa.

Resultados: Los análisis de regresión univariados mostraron asociaciones estadísticamente significativas entre MTHFR C677T y el conteo de glóbulos rojos [CGR] $(\mathrm{p}=0.019)$ y entre MTHFR C677T y el volumen corpuscular medio $(\mathrm{p}=0.015)$. Los análisis de regresión multivariables mostraron asociaciones estadisticamente significativas entre MTHFR C677T y los valores del volumen de paquete celular $(\mathrm{p}=0.019)$, entre MTHFR C677T y el conteo CGR $(\mathrm{p}=0.013)$ y entre MTHFR A1298C y la concentración media de hemoglobina corpuscular $(\mathrm{p}=0.026)$.

Conclusión: Este estudio transversal exploratorio ha generado estimados de asociaciones de fenotipo-genotipo informativos y novedosos, pero probablemente se necesitan estudios más amplios para determinar si las variantes especificas dentro de estos genes subyacentes en las vías de transmetilación y transulfuración, están relacionadas con la variabilidad fenotípica interindividual en HbSS.
\end{abstract}

Palabras clave: Variantes genéticas, variación fenotípica, anemia de células falciformes

West Indian Med J 2017; 66 (4): 511

\section{INTRODUCTION}

Sickle cell disease (SCD), the most common monogenic disorder in Jamaica and the wider Caribbean, refers collectively to a group of red blood cell disorders that are all based on the canonical replacement of glutamate by valine in position six of the human beta-globin chain, which generates a variant form of beta-globin called sickle haemoglobin $\left[\mathrm{HbS}\right.$ or $\left.\beta^{\mathrm{S}}\right]$ (1). Sickle cell anaemia [homozygous haemoglobin SS] (HbSS), the most clinically severe type of SCD, results from the homozygous inheritance of $\mathrm{HbS}$ and can result in an array of pathophysiological features, including sickled erythrocytes, vaso-occlusion, haemolysis, oxidative stress, activation of inflammatory mediators, endothelial cell dysfunction, and end-organ vasculopathy (2). These and other features are associated with a wide range of clinical manifestations, such as painful crises, leg ulcers, pulmonary hypertension, cerebrovascular events, and infections (3). Substantial inter-individual phenotypic variation is routinely seen among patients with $\mathrm{HbSS}$, but an explanation for this baffling and clinically farreaching observation has yet to be established (4).

The principal objective of this study was to explore the overarching view that inherited differences might underlie inter-individual phenotypic heterogeneity in HbSS. Previous reports on the potential contribution of 
co-inherited genetic influences (such as $\alpha$-thalassaemia genotype and $\beta$-haemoglobin haplotype) indicate that those genetic factors that have been studied hitherto do not completely explain the variation in clinical expression observed among patients with this condition (5). However, other putative genetic influences may, at least in part, account for such variation.

Our hypothesis is that polymorphisms within genes that underlie the handling of one-carbon and sulphur-containing moieties might contribute to individual differences in the capacity of patients with $\mathrm{HbSS}$ to accommodate accelerated haematopoietic rates. In particular, well-characterized functional variants within genes that code for the enzymes, methylene tetrahydrofolate reductase [MTHFR] (EC: 1.5.1.20), 5-methyltetrahydrofolate-homocysteine methyltransferase [MTR] (EC: 2.1.1.13), and cystathionine beta-synthase [CBS] (EC: 4.2.1.22), could affect crucial biosynthetic processes in intermediary metabolism, thereby influencing important, clinically relevant phenotypes (6). Previous reports have implicated variants within the MTHFR, MTR and CBS genes with the development of several disease conditions, such as neural tube defects and Down's syndrome (7-12). In HbSS, elevated red blood cell (RBC) turnover rates are typically accompanied by marginal or deficient dietary intakes, which together could result in reduced provision of important one-carbon and sulphur-containing metabolic precursors. If so, specific gene variants that express metabolite handling enzymes of lower activity might exacerbate potential shortfalls in supply, thus compromising the processing and synthesis of critical biomolecules, such as DNA, haem, and the tripeptide antioxidant, glutathione (GSH).

Therefore, these specific functional polymorphisms within genes of the transmethylation and trans-sulphuration pathways might be related to inter-individual differences in the capacity to respond to the heightened demands imposed by accelerated rates of haemolysis and haematopoiesis and hence might underlie phenotypic variability among HbSS patients. Accordingly, in this article, we report findings from a cross-sectional study, involving participants from an internationally recognized sickle cell clinic, that explores whether specific, well-characterized functional variants within the MTHFR, MTR and CBS genes are associated with interindividual phenotypic variation in $\mathrm{HbSS}$.

\section{SUBJECTS AND METHODS}

\section{Recruitment of participants}

Study participants with $\mathrm{HbSS}$ disease were selected from the Sickle Cell Clinic of the Sickle Cell Unit (SCU), Tropical Medicine Research Institute, The University of the West Indies, Mona, Jamaica. Patients who attend the clinic are recruited on a daily basis through a consecutive enrolment scheme. In a previously reported study (13), participants were selected from consecutive attendees over two different time periods (April 2000 to July 2002), referred to as Consec1 and Consec2. Consec1, representing the first set of consecutively recruited participants (April 2000), consisted of 99 enrolled patients. Consec2, representing the second set of consecutively recruited participants (April to July 2002), consisted of 272 enrolled patients. No formal power calculations for sample size estimation were performed, since there were no previously available bygenotype effect sizes for any of the tested phenotypic measures. The University Hospital of the West Indies/ The University of the West Indies, Mona, Faculty of Medical Sciences Ethics Committee approved the study and the protocol for the recruitment of participants. All participants provided written informed consent.

\section{Laboratory assays}

DNA was extracted from blood samples using a standard phenol/chloroform protocol (14). Genotyping was performed using polymerase chain reaction-based methods: with minor modifications, all genotyping was performed according to previously published protocols (6). Four biallelic polymorphisms were typed within two genes (MTHFR and MTR) involved in methyl group handling and $C B S$, a gene that codes for an enzyme of the trans-sulphuration pathway. Two common MTHFR polymorphisms were typed: MTHFR-C677T, where there is an alanine to valine conversion $(\mathrm{C} \rightarrow \mathrm{T}$ transition at nucleotide 677), and MTHFR-A1298C, where there is an alanine to glutamate change $(\mathrm{A} \rightarrow \mathrm{C}$ transversion at nucleotide 1298 in exon 7). For $M T R$, an A $\rightarrow \mathrm{G}$ polymorphism at nucleotide 2756, resulting in an aspartate to glycine conversion, was typed. For $C B S$, an 844ins68 variant, an insertion (I)/deletion (D)-type polymorphism of $68 \mathrm{bp}$ in exon 8 , was typed.

Steady-state haematological and laboratory values and bilirubin levels were obtained from the SCU database. Steady-state in SCD typically refers to a period of relatively good health and well-being, with no overt clinical symptoms of disease (15). The arithmetic means 
calculated from these database-derived values are used to represent, as far as possible, the 'normal' values for individuals.

\section{Statistical analyses}

The summary characteristics of the participants of the study were tabulated by gender: counts, proportions (percentages) or means plus or minus standard deviations are presented. For comparisons between the genders, the Chi-square test or Student's $t$-test was used, as appropriate. For some continuously distributed variables, a natural log transformation was performed in order to reduce heteroscedasticity.

Tests of association between the candidate genotypes and phenotypes were conducted using either univariate or multivariable linear regression models. For these regression analyses, regression coefficients, standard errors and $p$ values were calculated for each of the genetic markers, which were entered as indicator ('dummy') variables. The coefficients for the 'dummy' variables reflected the difference between the reference level (the 'wild type' for each genetic marker) and each of the other levels of the factor (the other genotypes for each marker). After adjustment for important covariates of age, gender and body mass index (BMI), multivariable linear regression was used to test for associations between genetic polymorphisms and levels of phenotypic variables. All statistical analyses were carried out using Stata 9 (College Station, TX, United States of America).

\section{RESULTS}

\section{Summary characteristics of the participants of the study}

The descriptive characteristics for the total set of 371 participants drawn from the SCU Clinic are displayed in Table 1. The total set of participants includes those selected from the Consec1 time period $(\mathrm{n}=99)$ combined with those selected from the Consec 2 time period $(n=272)$. For both time periods, all participants were recruited by a single researcher utilizing a single protocol (13). Preliminary analyses (not shown) prior to the merging of data from these separate time periods did not reveal any statistically significant differences between them.

Table 1 summarizes the values of the selected phenotypes of interest (namely, standard anthropometric measures, clinically relevant haematological variables and bilirubin concentrations) by gender. Fifty-three per cent of the study participants were female. The mean age of all of the participants was 34.4 ( \pm standard deviation,

Table 1: Summary descriptive statistics (mean \pm SD) for all participants, by gender

\begin{tabular}{lllll}
\hline Characteristic & Men & Women & Total & Reference range \\
\hline $\mathrm{n}(\%)$ & $173(47)$ & $198(53)$ & 371 & - \\
Age $($ year) & $33.6 \pm 10.7$ & $35.0 \pm 11.3$ & $34.4 \pm 11.0$ & - \\
$\mathrm{BMI}\left(\mathrm{kg} / \mathrm{m}^{2}\right)^{*}$ & $19.4 \pm 2.3$ & $20.9 \pm 3.5$ & $20.2 \pm 3.1$ & $18.5-24.9$ \\
$\mathrm{HbA}_{2}(\%)^{* *}$ & $3.2 \pm 0.4$ & $3.0 \pm 0.5$ & $3.1 \pm 0.4$ & $1.5-3.3$ \\
$\mathrm{HbF}(\%)^{*}$ & $5.2 \pm 4.2$ & $7.1 \pm 4.7$ & $6.3 \pm 4.6$ & $0-0.9$ \\
$\mathrm{Hb}(\mathrm{g} / \mathrm{dL})$ & $7.9 \pm 1.2$ & $7.9 \pm 1.0$ & $7.9 \pm 1.1$ & $12.0-17.0$ \\
$\mathrm{PCV}(\%)$ & $23.3 \pm 3.7$ & $23.1 \pm 3.3$ & $23.2 \pm 3.5$ & $36-50$ \\
$\mathrm{MCHC}(\mathrm{g} / \mathrm{dL})$ & $34.1 \pm 1.7$ & $34.2 \pm 1.8$ & $34.1 \pm 1.8$ & $31.0-37.0$ \\
$\mathrm{RBC}$ count $\left(\mathrm{x} 10^{12} / \mathrm{l}\right) *$ & $2.8 \pm 0.6$ & $2.6 \pm 0.4$ & $2.7 \pm 0.5$ & $3.6-5.1$ \\
$\mathrm{MCV}(\mathrm{fl}) *$ & $85.3 \pm 8.0$ & $89.7 \pm 6.9$ & $87.7 \pm 7.8$ & $80-100$ \\
$\mathrm{MCH}(\mathrm{pg}) *$ & $31.6 \pm 2.1$ & $32.5 \pm 1.9$ & $32.1 \pm 2.1$ & $26-34$ \\
$\mathrm{Reticulocyte}$ count $(\%)$ & $11.7 \pm 4.1$ & $11.4 \pm 3.3$ & $11.5 \pm 3.7$ & $<0.6$ \\
Total bilirubin $(\mu \mathrm{mol} / \mathrm{l})$ & $52.6 \pm 39.6$ & $47.9 \pm 27.7$ & $50.1 \pm 33.8$ & $2-14$ \\
Direct bilirubin $(\mu \mathrm{mol} / \mathrm{l})$ & $18.5 \pm 18.7$ & $16.0 \pm 6.6$ & $17.1 \pm 13.7$ & $0-4$ \\
Indirect bilirubin $(\mu \mathrm{mol} / \mathrm{l})$ & $34.1 \pm 29.9$ & $32.0 \pm 25.3$ & $33.0 \pm 27.5$ & $2-10$ \\
\hline
\end{tabular}

$\mathrm{BMI}=$ body mass index, $\mathrm{HbA}_{2}=$ haemoglobin $\mathrm{A}_{2}, \mathrm{HbF}=$ fetal haemoglobin, $\mathrm{Hb}=$ haemoglobin, $\mathrm{PCV}=$ packed cell volume, $\mathrm{MCHC}=$ mean cell haemoglobin concentration, $\mathrm{RBC}=$ red blood cell, $\mathrm{MCV}=$ mean corpuscular volume, $\mathrm{MCH}=$ mean corpuscular haemoglobin.

$* p<0.001, * * p<0.01$.

Student's $t$-test was performed to test for differences between men and women. 
$11.0)$ years. Women were slightly older than men, but there was no statistically significant difference in mean ages between the genders. With respect to anthropometry, the mean BMI for women $(20.9 \pm 3.5)$, while within the normal range $\left(18.5-24.9 \mathrm{~kg} / \mathrm{m}^{2}\right)$, was significantly higher $(p<0.001)$ than the mean BMI $(19.4 \pm 2.3)$ for men.

There were statistically significant differences between the genders with respect to mean $\mathrm{HbA}_{2}, \mathrm{HbF}$, $\mathrm{RBC}, \mathrm{MCV}$ and $\mathrm{MCH}$ values. The mean $\mathrm{HbA}_{2}$ was significantly higher $(p<0.01)$ in men $(3.2 . \pm 0.4 \%)$ than in women $(3.0 \pm 0.5 \%)$, as was the mean RBC count $\left(2.8 \pm 0.6 \times 10^{12} / 1\right.$ and $2.6 \pm 0.4 \times 10^{12} / 1$, respectively; $p<0.001)$. In contrast, the mean $\mathrm{HbF}$ value was significantly elevated $(p<0.001)$ in women $(7.1 \pm 4.7 \%)$ compared to men $(5.2 \pm 4.2 \%)$, with values for both genders being higher than the reference range of $0-0.9 \%$. The mean MCV was also significantly higher $(p<0.01)$ in women $(89.7 \pm 6.9 \mathrm{fl})$ compared to men $(85.3 \pm 8.0 \mathrm{fl})$. Similarly, the mean $\mathrm{MCH}$ was significantly higher $(p<0.01)$ in women $(32.5 \pm 1.9 \mathrm{pg})$ than in men $(31.6$ $\pm 2.1 \mathrm{pg})$.

For the total set of participants, the $\mathrm{HbA}_{2}$ percentages $(3.1 \pm 0.4 \%)$ were within the normal range (1.5-3.3\%), but reticulocyte counts $(11.5 \pm 3.7 \%)$ were elevated when compared to the reference $(<0.6 \%)$ and $\mathrm{RBC}$ values $\left(2.7 \pm 0.5 \times 10^{12} / 1\right)$ were lower than the reference range $\left(3.6-5.1 \times 10^{12} / 1\right)$. In addition, the total $(50.1 \pm 33.8 \mu \mathrm{mol} / \mathrm{l})$, direct $(17.1 \pm 13.7 \mu \mathrm{mol} / \mathrm{l})$ and indirect $(33.9 \pm 27.5 \mu \mathrm{mol} / \mathrm{l})$ bilirubin levels for all of the participants were higher than the corresponding reference ranges $(2-14 \mu \mathrm{mol} / 1,0-4 \mu \mathrm{mol} / 1$ and $2-10$ $\mu \mathrm{mol} / 1$, respectively). However, there were no statistically significant differences between men and women in the values of these variables.

\section{Univariate and multivariable tests of association between the candidate genetic markers and phenotypic variables}

Table 2 shows $p$ values for the univariate (unadjusted) tests of association between the candidate genetic markers and the measured phenotypic variables.

There was a statistically significant association ( $p=0.019$ ) between the MTHFR C677T marker and RBC count. The association between the MTHFR C677T marker and MCV was also statistically significant $(p=0.015)$. No other statistically significant associations between our set of genetic markers and the candidate phenotypic measures were obtained using univariate analyses.

Multivariable regression tests of association revealed three statistically significant associations between our candidate genetic markers and the phenotypic measures (Table 3).

After adjusting for age, gender and BMI, there was a statistically significant $(p=0.013)$ positive association between the MTHFR C677T C/T heterozygote and mean RBC levels, when compared with the reference $C / C$ homozygote. Similarly, there was a statistically significant $(p=0.019)$ positive association between

Table 2: $\quad p$ values obtained from the univariate regression of phenotypic variables on transmethylation or trans-sulphuration genotypes

\begin{tabular}{|c|c|c|c|c|}
\hline \multirow{2}{*}{ Phenotypic variable } & \multicolumn{4}{|c|}{ Gene variant } \\
\hline & MTHFR C677T & MTHFR A1298C & MTR A2756G & CBS 844ins68 \\
\hline $\mathrm{HbA}_{2}(\%)$ & 0.438 & 0.831 & 0.355 & 0.996 \\
\hline $\mathrm{HbF}(\%)$ & 0.544 & 0.089 & 0.428 & 0.308 \\
\hline $\mathrm{Hb}(\mathrm{g} / \mathrm{dL})$ & 0.386 & 0.566 & 0.166 & 0.657 \\
\hline PCV (\%) & 0.137 & 0.876 & 0.402 & 0.853 \\
\hline $\mathrm{MCHC}(\mathrm{g} / \mathrm{dL})$ & 0.262 & 0.145 & 0.405 & 0.370 \\
\hline $\mathrm{RBC}$ count $\left(\mathrm{x} 10^{12} / 1\right)$ & $0.019 *$ & 0.539 & 0.896 & 0.797 \\
\hline $\operatorname{MCV}$ (fl) & $0.015^{*}$ & 0.923 & 0.377 & 0.283 \\
\hline $\mathrm{MCH}(\mathrm{pg})$ & 0.063 & 0.993 & 0.323 & 0.501 \\
\hline Reticulocyte count $(\%)$ & 0.381 & 0.678 & 0.842 & 0.862 \\
\hline Total bilirubin $(\mu \mathrm{mol} / \mathrm{l})$ & 0.295 & 0.192 & 0.697 & 0.264 \\
\hline Direct bilirubin $(\mu \mathrm{mol} / \mathrm{l})$ & 0.412 & 0.419 & 0.185 & 0.887 \\
\hline Indirect bilirubin $(\mu \mathrm{mol} / \mathrm{l})$ & 0.454 & 0.245 & 0.912 & 0.205 \\
\hline
\end{tabular}

$* p<0.05$ 
Table 3: Regression coefficients $(B)$, standard errors and $p$ values obtained from the multivariable regression of haematological variables on MTHFR genotypes, adjusted for age, gender and BMI

\begin{tabular}{|c|c|c|c|c|}
\hline Phenotypic variable & Genotype & Coefficient $(B)$ & Standard error & $p$ value \\
\hline \multirow[t]{2}{*}{$\mathrm{RBC}$ count $\left(\mathrm{x} 10^{12} / 1\right)$} & MTHFR C677T C/T* & 0.179 & 0.072 & $0.013^{\#}$ \\
\hline & MTHFR C677T T/T* & 0.085 & 0.338 & 0.801 \\
\hline \multirow[t]{2}{*}{$\mathrm{PCV}(\%)$} & MTHFR C677T C/T* & 1.137 & 0.482 & $0.019^{\#}$ \\
\hline & MTHFR C677T T/T* & -0.358 & 2.273 & 0.875 \\
\hline \multirow[t]{2}{*}{$\mathrm{MCHC}(\mathrm{g} / \mathrm{dL})$} & MTHFR A1298C A/C** & 0.067 & 0.243 & 0.781 \\
\hline & MTHFR A1298C C/C** & 0.939 & 0.421 & $0.026^{\#}$ \\
\hline
\end{tabular}

\footnotetext{
* Reference genotype: MTHFR C677T C/C

** Reference genotype: MTHFR A1298C A/A

${ }^{*} p<0.05$
}

the MTHFR C677T C/T heterozygote and PCV values, although this was not seen for the $T / T$ variant. Our multivariable regression analyses also revealed a statistically significant $(p=0.026)$ positive association between the MTHFR A1298C T/T homozygote and mean MCHC levels, when compared with either the $C / C$ homozygote or $C / T$ heterozygote. No other statistically significant associations between our set of genetic markers and the candidate phenotypic measures were obtained using multivariable analyses.

\section{DISCUSSION}

Substantial inter-individual phenotypic variability in HbSS is both routinely observed and clinically significant (4), but the factors underlying such heterogeneity remain to be elucidated. It is conceivable, though, that inter-individual phenotypic variation in HbSS might be related to specific polymorphisms within genes underlying the transmethylation and trans-sulphuration pathways. So, in this cross-sectional clinic-based study, we explored that notion by investigating whether welldefined functional variants within the MTHFR, MTR and $C B S$ genes were associated with inter-individual phenotypic variation. We will discuss our results by focussing primarily on those statistically significant estimates of association that were derived from multivariable regression models.

For all the participants, we observed increases in bilirubin values that were in accordance with our expectations. In HbSS, accelerated intra-vascular haemolysis rates, leading to higher haem concentrations, would be expected to result in concomitantly increased rates of bilirubin synthesis, which can be used as a clinical marker of intra-vascular haemolysis (16). Consequently, we expected that bilirubin levels would be elevated among the participants and this was, indeed, what we observed, with levels of total, direct and indirect bilirubin all being above reference values. We then probed to discover whether there was any evidence of statistically significant genotype-bilirubin associations, since it was hypothesized that variants within the MTHFR, MTR and $C B S$ markers might be associated with differences in bilirubin measures. Neither univariate nor multivariable regression analyses revealed any such relationships. This could indicate that none of these specific genetic markers was actually related to inter-individual variation in bilirubin values, although we cannot discount the possibility that these variants might have exerted small yet real effects on the phenotype that were not captured because the study could have been statistically underpowered.

Previous reports have demonstrated marked differences in haematological measures when persons with SCD or other haemolytic anaemias are compared with controls. Specifically, HbSS, Hb, PCV and RBC values tend to be lower than normal, while reticulocyte count and $\mathrm{HbF}$ levels tend to be raised (17). We can confirm a similar pattern in the current study. We also explored whether markers within the MTHFR, MTR and $C B S$ genes were associated with differences in the levels of these variables. Potentially, variants within these genes might influence haematological values, since each of the enzymes coded for by these genes performs pivotal metabolic roles. For example, MTHFR catalyses the synthesis of 5-methyltetrahydrofolate, which acts as the methyl donor for the remethylation of homocysteine to form methionine, a reaction catalysed by MTR. On the other hand, CBS conjugates homocysteine to serine, a step on the pathway to the de novo synthesis of the amino acid cysteine, and ultimately the formation of GSH. Furthermore, in HbSS, 'steady state' levels for indices such as $\mathrm{MCV}, \mathrm{MCH}$ and $\mathrm{MCHC}$ might be maintained 
at the expense of an attenuated reserve capacity, so the influence of specific genetic variants on the levels of these haematological variables might be exposed in people with this condition.

In this study, we obtained three statistically significant associations between variants within the MTHFR gene and the haematological measures. More specifically, univariate regression analyses yielded statistically significant genotype-phenotype associations between the MTHFR C677T marker and RBC counts as well as between the MTHFR C677T marker and MCV values, whereas multivariable regression analyses (adjusted for age, gender and BMI) revealed significant associations between the MTHFR C677T marker and PCV levels, between the MTHFR C677T marker and RBC counts, and between the MTHFR A1298C marker and MCHC values. Previous reports indicate that either the $677 T$ or the $1298 \mathrm{C}$ variant of MTHFR can reduce enzyme activity, with a resulting decrease in the rate of methionine synthesis from homocysteine (11). When accompanied by low folate levels, it is possible that this might increase the pool of homocysteine available for cysteine synthesis or, in contrast, reduce the pool of methionine available for such processes as DNA methylation. Although this study was not designed to distinguish between such alternative metabolic fates, further studies may allow us to probe more deeply into the possible biological underpinnings of the observed relationships.

This investigation was explicitly exploratory in nature, and its most noticeable limitations reflect this. At the outset of the study, no prior data on effect sizes (ie the imputed influence of the specific genetic variants on phenotypic measures) were available. Therefore, this examination of putative genotype-phenotype associations was treated as an exploratory or 'discovery' exercise. Correspondingly, in the statistical analyses, no adjustments for multiple comparisons (using a method such as the Bonferroni correction) were made, thus increasing the possibility that some of the statistically significant estimates of association were generated by chance. However, this approach can be justified on the grounds that for this exploratory study, our principal aim was not to establish statistically significant relationships. Instead, we sought to generate preliminary estimates of associations between specific candidate genetic markers and the clinically relevant phenotypic measures, which can be used to guide decision-making related to sample size calculations in future larger studies.

While there were plausible reasons for thinking that this study might discover a greater number of statistically significant associations between our tested panels of genotypes and phenotypes, we, in fact, observed only a few such relationships. For example, we observed no statistically significant associations between any of our phenotypic measures and either the MTR A2756G marker or the CBS 844ins68 marker. It could be argued, though, that the relatively small number of significant associations obtained in this study was not particularly surprising. For many phenotypic outcomes, the role of genetic factors is small either in an absolute sense or relative to environmental factors (18). Hence, the influence of single genetic factors on such outcomes in HbSS might not have been uncovered here because the current exploratory study lacked sufficient statistical power to disclose the small but potentially important influence of these particular polymorphisms on inter-individual phenotypic variation. Nevertheless, the estimates that this study has generated are now available to inform the design of further studies that can test for these and other genotype-phenotype relationships in HbSS.

In conclusion, this exploratory cross-sectional study has tested for and generated a number of novel, informative and usable estimates of association between our tested panel of transmethylation and trans-sulphuration genetic variants and clinically relevant measures in HbSS. Our findings leave open the possibility that phenotypic heterogeneity in this condition could be influenced by the genetic factors that were analysed in this study. However, to examine these and other putative relationships more comprehensively, larger studies will be needed. Accordingly, we recommend that future studies involving larger participant samples and more extensive genetic analysis (eg genome-wide association studies) be conducted so as to facilitate the identification of those genetic variants that are not only associated with inter-individual phenotypic variability in HbSS but might also affect the clinical course of the condition.

\section{ACKNOWLEDGEMENTS}

We would like to thank the study participants from the Annual Sickle Cell Unit Cohort Review and the patients and staff of the Sickle Cell Unit for their assistance in this study.

\section{REFERENCES}

1. Hoban MD, Orkin SH, Bauer DE. Genetic treatment of a molecular disorder: gene therapy approaches to sickle cell disease. Blood 2016; 127: 839-48.

2. Gordeuk VR, Castro OL, Machado RF. Pathophysiology and treatment of pulmonary hypertension in sickle cell disease. Blood 2016; 127: 820-8. 
3. Rees DC, Gibson JS. Biomarkers in sickle cell disease. Br J Haematol 2011; 156: 433-45.

4. Telen MJ. Beyond hydroxyurea: new and old drugs in the pipeline for sickle cell disease. Blood 2016; 127: 810-9.

5. Cox SE, Makani J, Soka D, L'Esperence VS, Kija E, Dominguez-Salas $\mathrm{P}$ et al. Haptoglobin, alpha-thalassaemia and glucose-6-phosphate dehydrogenase polymorphisms and risk of abnormal transcranial Doppler among patients with sickle cell anaemia in Tanzania. Br J Haematol 2014; 165: 699-706.

6. Marshall KG, Howell S, Badaloo AV, Reid M, Farrall M, Forrester T et al. Polymorphisms in genes involved in folate metabolism as risk factors for oedematous severe childhood malnutrition: a hypothesisgenerating study. Ann Trop Paediatr 2006; 26: 107-14.

7. Garcia-Fragoso L, Garcia-Garcia I, Leavitt G, Renta J, Ayala MA, Cadilla CL. MTHFR polymorphisms in Puerto Rican children with isolated congenital heart disease and their mothers. Int J Genet Mol Biol 2010; 2: 43-7.

8. McNulty H, Pentieva K, Hoey L, Strain JJ, Ward M. Nutrition throughout life: folate. Int J Vitam Nutr Res 2012; 82: 348-54.

9. Kaur A. Maternal MTHFR polymorphism (677 C-T) and risk of Down's syndrome child: meta-analysis. J Genet 2016; 95: 505-13.

10. Botto LD, Yang Q. 5,10-Methylenetetrahydrofolate reductase gene variants and congenital anomalies: a HuGE review. Am J Epidemiol 2000; 151: $862-77$.
11. Fodinger M, Horl WH, Sunder-Plassmann G. Molecular biology of 5,10-methylenetetrahydrofolate reductase. J Nephrol 2000; 13: 20-33.

12. Moreira Neto F, Lourenco DM, Noguti MA, Morelli VM, Gil IC, Beltrao AC et al. The clinical impact of MTHFR polymorphism on the vascular complications of sickle cell disease. Braz J Med Biol Res 2006; 39: $1291-5$.

13. Haverfield EV, McKenzie CA, Forrester T, Bouzekri N, Harding R, Serjeant $\mathrm{G}$ et al. UGT1A1 variation and gallstone formation in sickle cell disease. Blood 2005; 105: 968-72.

14. Sambrook JF, Russell DW, eds. Molecular cloning: a laboratory manual, $3^{\text {rd }}$ edn. Cold Spring Harbor, NY: Cold Spring Harbor Laboratory; 2001.

15. Serjeant GR. The role of preventive medicine in sickle cell disease. The Watson Smith lecture. J R Coll Physicians Lond 1996; 30: 37-41.

16. Barcellini W, Fattizzo B. Clinical applications of hemolytic markers in the differential diagnosis and management of hemolytic anemia. Dis Markers; 2015: 635670.

17. Maude GH, Hayes RJ, Serjeant GR. The haematology of steady state homozygous sickle cell disease: interrelationships between haematological indices. Br J Haematol 1987; 66: 549-58.

18. Marshall KG, Swaby K, Hamilton K, Howell S, Landis RC, Hambleton IR et al. A preliminary examination of the effects of genetic variants of redox enzymes on susceptibility to oedematous malnutrition and on percentage cytotoxicity in response to oxidative stress in vitro. Ann Trop Paediatr 2012; 31: 27-36. 